\title{
Improved protocol to purify untagged amelogenin - Application to murine amelogenin containing the equivalent P70 CPT point mutation observed in human amelogenesis imperfecta.
}

Garry W. Buchko* and Wendy J. Shaw

Fundamental and Computational Sciences Directorate, Pacific Northwest National Laboratory, Richland, WA 99352, USA.

*Correspondence to: Garry W. Buchko, Pacific Northwest National Laboratory, Environmental Molecular Sciences Laboratory, Mail Stop: K8-98, Richland, WA 99352.

E-mail: garry.buchko@pnnl.gov 


\section{ABSTRACT}

Amelogenin is the predominant extracellular protein responsible for converting carbonated hydroxyapatite into dental enamel, the hardest and most heavily mineralized tissue in vertebrates. Despite much effort, the precise mechanism by which amelogenin regulates enamel formation is not fully understood. To assist efforts aimed at understanding the biochemical mechanism of enamel formation, more facile protocols to purify recombinantly expressed amelogenin, ideally without any tag to assist affinity purification, are advantageous. Here we describe an improved method to purify milligram quantities of amelogenin that exploits its high solubility in $2 \%$ glacial acetic acid under conditions of low ionic strength. The method involves heating the frozen cell pellet for two 15 min periods at $\sim 70{ }^{\circ} \mathrm{C}$ with two minutes of sonication in between, dialysis twice in $2 \%$ acetic acid $(1: 250 \mathrm{v} / \mathrm{v})$, and reverse phase chromatography. A further improvement in yield is obtained by resuspending the frozen cell pellet in $6 \mathrm{M}$ guanidine hydrochloride in the first step. The acetic acid heating method is illustrated with a murine amelogenin containing the corresponding P70 COT point mutation observed in an human amelogenin associated with amelogenesis imperfecta (P71T), while the guanidine hydrochloride heating method is illustrated with wild type murine amelogenin (M180). The self-assembly properties of P71T were probed by NMR chemical shift perturbation studies as a function of protein $(0.1$ to $1.8 \mathrm{mM})$ and $\mathrm{NaCl}(0$ to $367 \mathrm{mM}$ ) concentration. Relative to similar studies with wild type murine amelogenin, P71T self-associates at lower protein or salt concentrations with the interactions initiated near the Nterminus. 
Keywords: amelogenesis imperfecta; intrinsic disorder; amelogenin; tooth enamel; biomineralization; NMR spectroscopy.

Abbreviations used: hM180, full-length murine amelogenin with a 12-residue N-terminal tag; hP41T, murine amelogenin with a P41 Cे point mutation and 12-residue N-terminal tag; P71T, murine amelogenin with a P71 ट्ञ point mutation; hT21I, murine amelogenin with a T21 ट्ञ point mutation and 12-residue N-terminal tag; M180, full-length murine amelogenin; NMR, nuclear magnetic resonance; OD, optical density. 


\section{Introduction}

In the final stages of tooth development a 1-2 mm layer of enamel is deposited over the dentin [1]. Once mineralization is complete the enamel is not remodeled or repaired. Consequently, enamel has to last a lifetime, withstanding abrasion and fracture during mastication within the bacteria-filled environment of the mouth. Wear-resistance is achieved with a unique combination of high mineral content and high degree of architectural organization [2] that makes enamel the hardest tissue in the vertebrate body [1,3]. By weight, over $97 \%$ of mature enamel consists of carbonated hydroxyapatite crystals elongated in the c-axial direction and tightly packed into parallel arrays intricately crossed weaved into a unique lattice [4-6]. This process, amelogenesis, occurs over three stages (secretory, transition, and maturation) [7] with the cascade of events beginning with dentin triggered differentiation of specialized cells into ameloblasts. In the secretory-stage these ameloblasts secrete a cocktail of proteins into the extracellular environment around the dentin with enamel nucleation and growth occurring almost immediately thereafter [6,8-11]. During the transition-stage there is a progressive removal of matrix proteins by proteases, such as enamelysin (MMP-20) and kallikrein (KLK-4). At the end of the maturation-stage hard and tough enamel, largely devoid of organic material, remains to protect the dentin and other internal parts of the tooth for life.

Amelogenin is the primary protein secreted by ameloblasts and is largely responsible for guiding the nucleation, growth, and organization of brittle hydroxyapatite into tough enamel [6,8,11-13]. This low-molecular-weight protein $(\sim 22 \mathrm{kDa})$ is highly conserved among species [14] and can be divided into three parts as illustrated for murine amelogenin in Figure 1: an Nterminal tyrosine-rich region (TRAP) containing a post-translationally phosphorylated serine (S16), a central region rich in $\mathrm{P}, \mathrm{L}, \mathrm{H}$, and Q residues (HQP-rich region), and a hydrophilic C- 
terminal region. The charged amino acid residues at both termini are highly conserved suggesting that these regions serve important functional roles for mediating enamel biomineralization [15]. The central region is exclusively hydrophobic and responsible for one of the unique properties of amelogenin, an ability, under the proper environmental conditions present in the secretory-stage, to self-assemble into a quaternary structure, $40-100 \mathrm{~nm}$ in diameter, called a nanosphere [10]. These nanosphere structures have been observed both in vivo [10] and in vitro [9] and are believed to be an important functional form of the protein [16]. Assembly of individual amelogenin molecules into larger units is hypothesized to occur progressively $[17,18]$ with the process dependent on the sensitive interplay between protein concentration and the solution properties (ionic strength, $\mathrm{pH}$, solutes, and temperature) [18-22].

Amelogenesis imperfecta [23] is a group of hereditary conditions associated with six genes that affect the quantity and quality of enamel [24,25]. Clinical phenotypes of the mutations to these genes vary and include hypomaturation, hypoplasia, and hypocalcification. The majority of genetic mutations associated with amelogenesis imperfecta is in the gene for amelogenin [26] and includes a single amino acid substitution, P70 der, in the primary amino acid sequence of human amelogenin [27]. The phenotype of the P70 COT mutation is hypomineralized enamel with a higher than normal protein content [27]. In vitro studies showed that proteolysis by MMP20 was decelerated in amelogenin containing the P70 COr substitution [28] and relative to wild type amelogenin, this mutated form of the protein formed larger nanospheres [29]. Two other single point mutations identified in the amelogenin gene, T21 Cy and P40 C8T, were also shown to affect the self-assembly properties of amelogenin relative to the wild type protein $[26,30,31]$. 
The ability to express and purify large quantities of amelogenin is important for studies aimed at understanding its role in biomineralization. This is especially important for solutionand solid-state NMR experiments that require upwards of 5 and 50 milligrams of protein, respectively, for a single sample. In addition, amelogenin and its splice variants/proteolytic digestion products may have biological properties similar to signaling molecules [32,33], and consequently, potential clinical uses [34]. Amelogenin also has a proposed role in the synthesis of novel biomaterials [35] and as a fusion partner to purify target proteins/peptides [36]. The later potential use for amelogenin exploits the protein's high solubility under acidic conditions (2\% acetic acid) [37] and enables the purification of untagged recombinant amelogenin in a onestep protocol [36]. The reported one-step protocol involves heat treating cells $\left(80{ }^{\circ} \mathrm{C}\right)$ in $3 \%$ acetic acid and isolating the soluble fraction by centrifugation to yield amelogenin that is $\sim 95 \%$ pure. While yields of up to $1 \mathrm{~g} / \mathrm{L}$ were reported using TB-medium, we could not duplicate these yields using minimal media necessary to incorporate NMR isotopes (nitrogen-15 and carbon-13). Here, we report modifications that increase the yield in minimal media and allow the facile preparation of large quantities of carbon-13 and/or nitrogen-15 labeled amelogenin necessary for solution- and solid-state NMR spectroscopy. Our modifications to the purification protocol are demonstrated with untagged murine amelogenin (M180) and an untagged murine amelogenin containing the corresponding P70 28 point mutation observed in human amelogenin that is associated with amelogenesis imperfecta (P71 28T, P71T, relative to human amelogenin, murine amelogenin contains an extra methione at the 29th position). The ${ }^{1} \mathrm{H}-{ }^{15} \mathrm{~N}$ HSQC NMR spectrum of M180 in 2\% acetic acid is compared to the previously reported spectrum for M180 containing a 12-residue, hexa-histidine tag (MRGSHHHHHHGS-, hM180). To probe the finer molecular details of how the P71 COr point mutation may affect the self-assembly properties of P71T, this 
protein was characterized in solution using NMR spectroscopy under conditions that promote self-assembly, increasing protein concentration and ionic strength [18,22,38].

\section{Materials and methods}

All chemicals were purchased from Research Products International Corporation (Mount Prospect, IL) except trifluroacetic acid (TFA), glacial acetic acid, and HPLC grade acetonitrile (Sigma Chemical Company, St. Louis, MI).

Construction of expression vectors and protein expression

The genes for full-length wild type murine amelogenin (M180) [39] plus the site directed P71 ETT mutation (P71T), codon-optimized for Escherichia coli expression, were synthesized and inserted into the expression vector pJexpress414 (DNA 2.0 Inc, Menlo Park, CA). The recombinant plasmids were transformed into E. coli BL21(DE3) cells (Novagen, Madison, WI) following a heat shock method. Using the antibiotic ampicillin $(150 \mu \mathrm{g} / \mathrm{mL}), 15 \%$ glycerol stocks ( $\left.1 \mathrm{~mL}, \mathrm{OD}_{600} \approx 0.8\right)$ were prepared (from single colonies grown on LB agar plates) and stored at $-80{ }^{\circ} \mathrm{C}$ until ready for use. Uniformly ${ }^{15} \mathrm{~N}$-labeled protein was prepared using an autoinduction protocol [40] starting with a $20 \mathrm{~mL} \mathrm{LB}$ culture $\left(37^{\circ} \mathrm{C}\right)$ seeded with $1 \mathrm{~mL}$ of frozen

glycerol stock. At an $\mathrm{OD}_{600} \approx 0.8$, the $20 \mathrm{~mL}$ culture was directly transferred to $500 \mathrm{~mL}$ of autoinduction minimal media. Growth continued at $37^{\circ} \mathrm{C}$ until an $\mathrm{OD}_{600}$ of $\sim 0.8$ was reached 
and the cell culture transferred to a $25^{\circ} \mathrm{C}$ shaker. Following overnight incubation the cells were

harvested by mild centrifugation and stored at $-80{ }^{\circ} \mathrm{C}$. Uniformly ${ }^{15} \mathrm{~N}-,{ }^{13} \mathrm{C}$-labelled P71T and M180 were obtained in a similar manner except for the transfer of the $20 \mathrm{~mL} \mathrm{LB}$ culture into 750 $\mathrm{mL}$ of minimal media (Miller) containing ${ }^{15} \mathrm{NH}_{4} \mathrm{Cl}(1 \mathrm{mg} / \mathrm{mL})$ and $\mathrm{D}-\left[{ }^{13} \mathrm{C}_{6}\right] \mathrm{glucose}(2.0 \mathrm{mg} / \mathrm{mL})$, $\mathrm{NaCl}(50 \mu \mathrm{g} / \mathrm{mL}), \mathrm{MgSO}_{4}(120 \mu \mathrm{g} / \mathrm{mL}), \mathrm{CaCl}_{2}(11 \mu \mathrm{g} / \mathrm{mL})$, and ampicillin $(150 \mu \mathrm{g} / \mathrm{mL})$. When the cell culture reached an $\mathrm{OD}_{600}$ reading of $\sim 0.8$, it was transferred to a $298 \mathrm{~K}$ incubator and protein expression induced with isopropyl $\beta$-D-1-thiogalactopyranoside $(0.026 \mu \mathrm{g} / \mathrm{mL})$. After four hours the cells were harvested by mild centrifugation and stored at $-80{ }^{\circ} \mathrm{C}$.

\section{Protein purification}

The frozen pellet was resuspended $\left(500 \mathrm{~mL}\right.$ autoinduction minimal media $\left({ }^{15} \mathrm{~N}\right.$-labeled $)$ or $750 \mathrm{~mL}$ M9 minimal media $\left({ }^{13} \mathrm{C}\right.$ - and ${ }^{15} \mathrm{~N}$-labeled) $)$ in $40 \mathrm{~mL}$ of $2 \%$ glacial acetic acid and placed in a $70{ }^{\circ} \mathrm{C}$ water bath for 15 minutes. The suspension was then sonicated (without cooling) for 2 minutes and returned to the $70{ }^{\circ} \mathrm{C}$ for an additional 15 minutes. To demonstrate the advantage of dialysis, the lysed cells from a $500 \mathrm{~mL}$ autoinduction growth was split into two equal fractions and resuspended in $20 \mathrm{~mL}$ of $2 \%$ acetic acid. For one fraction, the insoluble cell debris was immediately removed by centrifugation at $25,000 \mathrm{~g}$ for $1 \mathrm{~h}$. For the other fraction, the solution was placed in dialysis tubing with a 3,500 dalton molecular weight cutoff (Fisher Scientific, Waltham, MA) and dialyzed sequentially against five liters of $1 \%(\sim 6 \mathrm{~h})$ and $2 \%(\sim 12$ h) glacial acetic acid (1:250, v:v) before removing the insoluble cell debris in a similar centrifugation manner. The supernatants were applied onto an XBridge Prep C18 (5 $\mu \mathrm{m}, 10 \times 250$ $\mathrm{mm}$ ) reverse phase column (Waters, Milford, MA) with the following purification gradient 
applied after loading the material using 100\% Buffer A (Buffer A = water in 0.1\% TFA, Buffer $\mathrm{B}=70 \%$ aq. $\mathrm{CH}_{3} \mathrm{CN}$ in $0.1 \%$ TFA, flow rate $2.5 \mathrm{~mL} / \mathrm{min}$ : Step $1-0.5 \mathrm{CV}, 100 \%$ Buffer A; Step $2-0.2 \mathrm{CV}$, linear gradient 0 to $40 \%$ Buffer B; Step $3-4.0 \mathrm{CV}$, linear gradient 40 to $100 \%$ Buffer B). The fractions containing amelogenin eluted at $\sim 68 \%$ Buffer B. These fractions were pooled, frozen at $-80^{\circ} \mathrm{C}$, and lyophilized. After weighing on an analytical scale, the material was resuspended in the appropriate buffer for subsequent analyses (an NMR buffer consisting of $2 \%$ $\mathrm{CD}_{3} \mathrm{CO}_{2} \mathrm{D}, 7 \% \mathrm{D}_{2} \mathrm{O} / 91 \% \mathrm{H}_{2} \mathrm{O}, \mathrm{pH} 2.8$ ) [22].

Further improvement in the amelogenin yields were obtained using the above protocol except for the resuspension of the frozen pellet $\left(500 \mathrm{~mL}\right.$ autoinduction minimal media $\left({ }^{15} \mathrm{~N}\right.$ labeled) or $750 \mathrm{~mL}$ M9 minimal media $\left({ }^{13} \mathrm{C}\right.$ - and ${ }^{15} \mathrm{~N}$-labeled) $)$ in $40 \mathrm{~mL}$ of $6 \mathrm{M}$ guanidine hydrochloride (unadjusted $\mathrm{pH} \sim 4.8$ ). To demonstrate the advantage of using the chaotropic agent, harvested cells from a $500 \mathrm{~mL}$ autoinduction growth of $\mathrm{M} 180$ was split into two equal fractions with one fraction resuspended in $20 \mathrm{~mL}$ of $6 \mathrm{M}$ guanidine hydrochloride solution and the other in $20 \mathrm{~mL}$ of $2 \%$ glacial acetic acid. Both solutions were heat treated as described above with the $2 \%$ acetic acid solution processed in an identical manner. On the other hand, the $6 \mathrm{M}$ guanidine hydrochloride solution was first centrifuged for $25,000 \mathrm{~g}$ for $1 \mathrm{~h}$ to remove cellular debris and the supernatant then dialyzed twice in $5 \mathrm{~L}$ of $2 \%$ glacial acetic acid. Following dialysis, precipitated material was removed by another centrifugation at $25,000 \mathrm{~g}$ for $45 \mathrm{~min}$ with the products in the supernatant analyzed by reverse phase HPLC chromatography and SDS PAGE.

NMR analysis 
All NMR data was collected at $20^{\circ} \mathrm{C}$ using a Varian Inova-750 spectrometer and Biopack pulse programs. Three-dimensional HNCACB data was collected on the double-labeled M180 and P71T samples to verify the amide chemical shift assignments that were otherwise based primarily on comparison to the ${ }^{1} \mathrm{H}^{15} \mathrm{~N}$ HSQC spectrum of previously assigned hM180 containing the non-removable N-terminal tag MRGSHHHHHHGS- [37].

For the dilution study, an initial $1.8 \mathrm{mM}$ sample of P71T was prepared in the NMR buffer. The initial ${ }^{1} \mathrm{H}^{15} \mathrm{~N}$ HSQC was collected on a $250 \mu \mathrm{L}$ sample in a Shigemi NMR tube (Shigemi Inc., Allison Park, PA) with subsequent spectra collected following serial dilutions to $0.9,0.45,0.22$, and $0.1 \mathrm{mM}$. For the $\mathrm{NaCl}$ titration study, a $2 \mathrm{M} \mathrm{NaCl}$ stock solution was prepared in NMR buffer. Seven and one half microliter aliquots of the sodium chloride stock solution were added directly to the amelogenin sample $(0.25 \mathrm{mM}(300 \mu \mathrm{L}))$ and, following gentle agitation, a high resolution ${ }^{1} \mathrm{H}-{ }^{15} \mathrm{~N}$ HSQC spectrum $\left(20{ }^{\circ} \mathrm{C}\right)$ was immediately acquired. NMR spectra were recorded in the absence of salt and at $\mathrm{NaCl}$ :protein molar ratios of 200, 400, $600,800,1000,1200,1400,1600$, and 1800 to one. At the end of the titration, due to dilution, the final concentration of $\mathrm{P} 71 \mathrm{~T}$ and $\mathrm{NaCl}$ was $0.204 \mathrm{mM}$ and $367 \mathrm{mM}$, respectively, in a final volume of $368 \mu \mathrm{L}$. All NMR data was processed using Felix2007 (Felix NMR, Inc, San Diego, CA) and analyzed using Sparky (v 3.115) [41]. The ${ }^{1} \mathrm{H},{ }^{13} \mathrm{C}$, and ${ }^{15} \mathrm{~N}$ chemical shifts referenced to DSS (DSS $=0 \mathrm{ppm})$ using indirect methods [42].

\section{Results}




\section{Protein purification.}

Recombinant human, porcine, and marine amelogenin have been used in many studies with the general purification protocol following the method first reported by Simmer et al. [43]: cell lysis under denaturing conditions (6 M guanidine hydrochloride), centrifugation, ammonium sulfate precipitation, and reverse phase chromatography. The yields of amelogenin reported using this method are modest (4 $-11 \mathrm{mg} / \mathrm{L}$ cell culture) [36] and may be improved (up to 70 $\mathrm{mg} / \mathrm{L}$ ) by adding an $\mathrm{N}$-terminal histidine tag to the protein $[22,31,44]$. Unfortunately, the nanosphere forming properties of amelogenin in solutions of high ionic strength or $\mathrm{pH}$ values above 6 , conditions employed by common proteases, makes the removal of many terminal polyhistidine tags difficult. Hence, the one-step protocol reported by Bonde et al. [36] without a purification tag is an attractive alternative to prepare large quantities (10s of $\mathrm{mg}$ ) of amelogenin. Our initial efforts to prepare ${ }^{15} \mathrm{~N}$-labeled $\mathrm{hM} 180$ following the one-step protocol using autoinduction minimal media produced much poorer yields than our standard method using metal-affinity chromatography [31]. These yields were reduced further when using an M9 minimal media protocol with isopropyl $\beta$-D-1-thiogalactopyranoside (IPTG) induction to generate ${ }^{13} \mathrm{C}$ - and ${ }^{15} \mathrm{~N}$-labeled protein (data not shown). Because Bonde et al. [36] did report that their yields increased when the volume of acetic acid used for cell lysis was increased from 60 to $600 \mathrm{~mL}$ (for a 1 liter culture), we surmised that the high ionic strength of the cell lysis solution in $3 \%$ acetic acid might result in amelogenin aggregation [22] and much of its removal in the cell pellet following centrifugation. Therefore, instead of lysing the cells in a large volume of acetic acid solution to lower the ionic strength we decided to reduce the ionic strength by dialyzing the cell lysis fraction in an acetic acid solution. 
The P71T cells from a $500 \mathrm{~mL}$ autoinduction growth in minimal media containing ${ }^{15} \mathrm{NHCl}_{4}$ were divided equally and resuspended in $20 \mathrm{~mL}$ of $2 \%$ acetic acid. Both fractions were lysed similarly following a combination protocol described by Bonde et al. [36]: 15 min in a 70 ${ }^{\circ} \mathrm{C}$ water bath, 2 min sonication while warm, and a further 15 min in a $70{ }^{\circ} \mathrm{C}$ water bath. The cell debris for one fraction was removed by centrifugation and the supernatant assayed by SDS PAGE and reverse phase HPLC. For the other fraction the entire cell lysis material was placed in dialysis tubing with a 3,500 MW cut-off and dialyzed sequentially in $5 \mathrm{~L}$ of $1 \%$ acetic acid followed by $5 \mathrm{~L}$ of $2 \%$ acetic acid $\left(5^{\circ} \mathrm{C}\right)$ before removing the cell debris by centrifugation and analyzing the supernatant by SDS-PAGE and reverse phase HPLC. The SDS-PAGE gel shown in Figure 2 illustrates the expression of a dominant band in the total cell lysis fraction (Lane A) with a molecular weight of $\sim 22 \mathrm{kDa}$, as expected for P71T. Upon centrifugation, the major product in the supernatant is still the band corresponding to P71T with many of the impurities removed (Lane 0). The intensity of this dominant band increases over two 1:250 (v:v) dialyses (Lanes 1 and 2). A better quantification of the products and impurities in the various fractions is afforded by reverse phase HPLC as illustrated in Figure 3A, profiles of the supernatant following centrifugation of the fraction without (red) and following $2 \mathrm{x}$ dialysis (black). Clearly, there is an $\sim$ 3-fold increase in the band at $\sim 36$ min corresponding to P71T. Moreover, following dialysis there is a substantial decrease in the band corresponding to unknown impurities that elutes at $23 \mathrm{~min}$ and a yellow/brown tinge color of the supernatant without dialysis is eliminated following two dialysis cycles. In summary, dialysis of the cell lysis material in $2 \%$ acetic before centrifugation increases the yield of amelogenin and reduces the impurities in the supernatant. Further purification by reverse phase chromatography removes impurities present after dialysis. 
For P71T using a minimal media autoinduction protocol the yield of ${ }^{15} \mathrm{~N}$-labeled amelogenin improved from $\sim 50 \mathrm{mg} / \mathrm{L}$ to almost $150 \mathrm{mg} / \mathrm{L}$.

While the SDS PAGE in Figure 2 shows that the amount of amelogenin in the soluble fraction increases with dialysis in 2\% acetic acid, the intensity of the P71T band in Lane A was greater than the corresponding band in Lane 2 suggesting that much amelogenin is lost in the cell pellet during centrifugation. To determine if this amelogenin could be recovered and the yield further improved, the cell pellet following centrifugation after $2 \mathrm{x}$ dialysis in acetic acid was resolubilized in $20 \mathrm{~mL}$ of $6 \mathrm{M}$ guanidine hydrochloride and then dialyzed $2 \mathrm{x}$ in $5 \mathrm{~L}$ of $2 \%$ acetic acid. During dialysis, a substantial amount of material precipitated our of solution. This precipitant was removed by centrifugation and the soluble material present in this fraction is illustrated in Lane G in Figure 2. Clearly, the $6 \mathrm{M}$ guanidine hydrochloride treatment recovered more P71T. While additional impurities are present in this fraction, they are eliminated by reverse phase HPLC chromatography (Figure 2, Lane 4).

To determine if better yields of amelogenin could be obtained by heating in $6 \mathrm{M}$ guanidine hydrochloride instead of $2 \%$ acetic acid, M180 cells from a $500 \mathrm{~mL}$ autoinduction growth in minimal media containing ${ }^{15} \mathrm{NHCl}_{4}$ were divided equally with one fraction resuspended in $2 \%$ acetic acid $(20 \mathrm{~mL})$ and the other fraction resuspended in $6 \mathrm{M}$ guanidine hydrochloride $(20 \mathrm{~mL})$. Both fractions were lysed as described for P71T. Insoluble cell debris from the $6 \mathrm{M}$ guanidine hydrochloride fraction was removed by centrifugation prior to dialysis of the supernatant $2 \mathrm{x}$ in $5 \mathrm{~L}$ of $2 \%$ acetic acid. Again, during dialysis a substantial amount of material precipitated out of solution. Figure 3B is the reverse phase HPLC profile of the M180 supernatant following centrifugation for the fraction lysed in $2 \%$ acetic acid (black) and guanidine hydrochloride (purple). While there are a few additional minor impurities from the 
fraction lysed in guanidine hydrochloride, there is an $\sim 2$-fold increase in the band at $\sim 36$ min corresponding to M180. In summary, the yield of amelogenin can be further improved by heat lysing the cells in $6 \mathrm{M}$ guanidium hydrochloride instead of $2 \%$ acetic acid prior to dialysis in $2 \%$ acetic acid. While this protocol results in some additional impurities in the supernatant following dialysis, most can be removed by reverse phase chromatography. For M180 using a minimum media autoinduction protocol the yield of ${ }^{15} \mathrm{~N}$-labeled amelogenin improved from $\sim 120 \mathrm{mg} / \mathrm{L}$ to over $200 \mathrm{mg} / \mathrm{L}$.

Note that while SDS PAGE analysis suggested the supernatant after dialysis and centrifugation was quite pure for P71T cells lysed in $2 \%$ acetic acid, the supernatant did have a faint yellow/brown color. This color was more pronounced for the cells lysed in $6 \mathrm{M}$ guanidine hydrochloride. Using either method, this color disappeared following reverse phase HPLC chromatography suggesting that the second purification step is beneficial especially since the nature of this impurity is unknown. Regardless of the identity of the impurity, ${ }^{1} \mathrm{H}-{ }^{15} \mathrm{~N} H S Q C$ spectra of supernatant with and without dialysis (lyophilization and resuspension in $2 \%$ acetic acid at approximately equal protein concentrations) suggested it promoted self-association of the amelogenin. The cross peaks in the spectrum for the undialyzed protein were very broad and many expected resonances were missing while the spectrum following dialysis was much sharper and complete (vida infra, data not shown). Hence, for the NMR studies for P71T and M180 described below, both proteins were further purified by reverse phase chromatography after heat treatment and dialysis. 
Figure 4 is an overlay of the ${ }^{1} \mathrm{H}^{-15} \mathrm{~N}$ HSQC spectrum of M180 and hM180 under conditions where hM180 was previously shown to be monomeric in solution $(0.3 \mathrm{mM}$ protein concentration, $2 \%$ acetic acid, $\left.\mathrm{pH} 2.8,20^{\circ} \mathrm{C}\right)[22]$. The most noticeable differences are the additional resonances due to the N-terminal tag in hM180 (labeled in red and an asterisk) and the amide chemical shifts for L3 (labeled and circled blue). The latter observation is most likely because L3 is the penultimate residue at the N-terminus of M180 (the N-terminal methionine is removed in E. coli by methionine aminopeptidase) [36] but is many residues removed from the N-terminal residue in hM180. While the other parts of the spectra do not overlap exactly, they are very similar (the proton chemical shift range in Figure 4 is only $0.8 \mathrm{ppm}$ ) indicating the Nterminal tag in hM180 has little influence on the structure adopted by the rest of the protein under these conditions, and concomitantly, perhaps little influence on the self-assembly properties of amelogenin under these conditions [22]. Another consequence of the similarity of the ${ }^{1} \mathrm{H}^{-15} \mathrm{~N}$ HSQC spectrum of M180 with hM180 is that a rapid assignment of the backbone ${ }^{1} \mathrm{H}^{\mathrm{N}}$ and ${ }^{15} \mathrm{~N}$ amide resonances for M180 was possible from the previous assignments of hM180 [37] with confirmation with a HNCACB data set for M180.

Figure 5 is an overlay of the ${ }^{1} \mathrm{H}-{ }^{15} \mathrm{~N}$ HSQC spectrum of P71T (yellow) with M180 (black) under conditions where hM180 was previously shown to be monomeric in solution (0.1 $\mathrm{mM}$ protein concentration, $2 \%$ acetic acid, $\mathrm{pH} 3,20^{\circ} \mathrm{C}$ ) [22]. While the majority of the amide assignments for P71T could be made by comparison to the amide assignments for M180, an HNCACB data set was collected to assign T71 and any residues with significant chemical shift perturbations. The new amide resonance, T71, overlaps with the amide resonance for H91 as illustrated in Figure 5. Aside from three resonances around the site of the P71 28T substitution 
(L70, V72, and V73 circled in Figure 5), the spectra for P71T and M180 overlay well suggesting that the amino acid substitution has little effect on the global structure of amelogenin. Such a highly localized chemical shift effect as a result of a single amino acid substitution is consistent with an intrinsically disordered protein, as reported for porcine [45] and murine [22] amelogenin. Local electronic differences due to the P71 dr change in P71T is likely responsible for the observed chemical shift perturbations. Note that one consequence of assigning the ${ }^{1} \mathrm{H}-{ }^{15} \mathrm{~N}$ HSQC spectra of M180 and P71T was the identification of a mis-assignment in the originally published spectrum for hM180 [37] that exchanges the assignments for V72 and V53.

Protein concentration effects on the self-assembly of P71T

The collection of ${ }^{1} \mathrm{H}^{15}{ }^{15} \mathrm{~N}$ HQC spectra at different protein concentrations is routinely used to assess concentration dependent self-association or transient aggregation of NMR samples. Here, it was clearly observed that the ${ }^{1} \mathrm{H}^{15} \mathrm{~N}$ HSQC spectra of P71T changed as the protein concentration was increased from $0.1 \mathrm{mM}$ to $1.8 \mathrm{mM}$ : the amide cross peaks became broader and ten additional peaks disappeared (spectra not shown). These observations suggest that P71T self-associates to form a larger molecular weight complex as the protein concentration is increased [31]. The disappearance of amide cross peaks in the ${ }^{1} \mathrm{H}-{ }^{15} \mathrm{~N}$ HSQC spectrum at higher protein concentrations is likely due to restricted motion and/or heterogeneous interactions at a protein-protein interface as interpreted previously for $\mathrm{hM} 180$ as a function of increasing $\mathrm{NaCl}$ and $\mathrm{CaCl}_{2}$ concentrations $[22,46]$. It was possible to track the disappearance of most of the amide cross peaks in the ${ }^{1} \mathrm{H}-{ }^{15} \mathrm{~N}$ HSQC spectra over the concentration range and this data for 
P71T is summarized in Fig. 6 along with previously presented data for two other murine amelogenin mutant proteins associated with amelogenensis imperfecta, T21 dy (hT21I) and P40 28T (hP41T) [31]. At $1.8 \mathrm{mM}$ concentration, the amide resonances that disappear in the ${ }^{1} \mathrm{H}$ -

${ }^{15} \mathrm{~N}$ HSQC spectrum of P71T are all localized near the N-terminus between V19 - Q32, a region similar to the one containing vanishing resonances in $\mathrm{hP} 41 \mathrm{~T}(\mathrm{~T} 21-\mathrm{Y} 37)$ at this protein concentration. In contrast, hT21I was much more sensitive to concentration and at $1.8 \mathrm{mM}$, resonances were largely absent for a large $\mathrm{N}$-terminal region between L3 - H58 and a C-terminal region between L142 - A170. Note that for native hM180, no amide resonances disappeared over this concentration range and only a broadening of cross peaks were observed as the protein concentration was increased to $1.8 \mathrm{mM}$. Overall, these results suggest that the mutated proteins begin to self-assemble at a lower protein concentration than the wild type protein in the order $\mathrm{hT} 21 \mathrm{I}<\mathrm{hP} 41 \mathrm{~T}=\mathrm{P} 71 \mathrm{~T}<\mathrm{hM} 180$.

Sodium chloride effects on self-assembly

By monitoring the disappearance of amide cross peaks in the ${ }^{1} \mathrm{H}-{ }^{15} \mathrm{~N}$ HSQC of hM180, $\mathrm{hT} 21 \mathrm{I}$, and $\mathrm{hP} 41 \mathrm{~T}$ as a function of increasing $\mathrm{NaCl}$ it was previously shown that increasing ionic strength affected a stepwise self-assembly of amelogenin into larger complexes [22, 31]. Like the concentration titrations studies, this association was largely followed by the disappearance of amide resonances in ${ }^{1} \mathrm{H}_{-}{ }^{15} \mathrm{~N}$ HSQC spectra as a function of increasing $\mathrm{NaCl}$ concentrations and is summarized for P71T in Figure 7. Furthermore, by collecting a series of ${ }^{1} \mathrm{H}-{ }^{15} \mathrm{~N}$ HSQC spectra at more closely spaced titration points it was possible to more finely identify the regions of P71T 
responsible for initiating self-assembly. At the first titration point, a $\mathrm{NaCl}$ :P71T molar ratio of 200:1, there was little change in the ${ }^{1} \mathrm{H}-{ }^{15} \mathrm{~N}$ HSQC spectrum of P71T aside from some mild line broadening (hence, this data is not shown in Figure 7). At the next titration point, a $\mathrm{NaCl}: \mathrm{P} 71 \mathrm{~T}$ molar ratio of 400:1, cross peaks for four out of the seven resonances between Y26 and Q32 disappear while the intensity of the remaining resonances change little, suggesting that the selfassembly process is initiated in this region. Upon further increase of the salt concentration additional resonances disappear in a fan-like fashion about this region with all the amide cross peaks for the residues between H6 - L54 gone at a NaCl:P71T molar ratio 1400:1. Near the Cterminal, the first amide resonance to disappear is $\mathrm{S} 152$ at a NaCl:P71T molar ratio of 600:1 and at 1400:1 ratio this region has expanded to include the disappearance of all the resonances between L147 - W168. At the final titration point, a NaCl:P71T molar ratio of 1800:1, any

resonance that has not disappeared completely is greatly reduced in intensity. In general, a similar pattern was observed for hM180, hT21I, and hP41T as a function of increasing $\mathrm{NaCl}$ concentration [31] with self-assembly due to increased $\mathrm{NaCl}$ accelerated for hT21I $>\mathrm{hP} 41 \mathrm{~T}>$ M180. Relative to these later three proteins, P71T behaved most closely to hP41T, as observed in the concentration titration.

\section{Discussion}

Using our improved purification approach it is possible to obtain large quantities of isotopically labeled recombinant amelogenin without the need for the introduction of a tag onto the primary sequence to assist protein purification or the use of large volumes of solvent to lyse 
the cells. While the NMR data presented here show that the structure for full-length native murine amelogenin, with and without the N-terminal polyhistidine tag, is essentially the same at $0.3 \mathrm{mM}$ protein concentrations in $2 \%$ acetic acid, removing the tag removes any concerns about it possibly influencing the self-assembly process, especially under more physiologically relevant conditions. Its removal may be especially important given that the N-terminal region of hM180 is the region first affected in the process of self-assembly induced by increasing salt concentrations [22], a region identified in playing a role in porcine amelogenin self-assembly induced by 2,2,2-trifluoroethanol [47], and a region implicated in self-assembly at a more physiological $\mathrm{pH}$ (5.5) by NMR experiments using a series of truncated murine amelogenin sequences [48]. Furthermore, the highly conserved [14] N-terminal region, M1-M42, has been identified by yeast two-hybrid assays [49] as essential for nanosphere self-assembly and it has been postulated that upon nanosphere formation this terminal is surface exposed $[9,16,20,49]$, increasing the nanosphere's solubility and enhancing its interactions with calcium phosphate $[15]$.

At $0.1 \mathrm{mM}$ protein concentration in $2 \%$ acetic acid, $\mathrm{P} 71 \mathrm{~T}$ is a monomeric, intrinsically disordered protein and relative to wild type amelogenin the single P71 COT substitution had little, if any, effect on the protein's structure. As the protein concentration or $\mathrm{NaCl}$ concentration was increased, the broadening and eventual disappearance of amide cross peaks in the ${ }^{1} \mathrm{H}_{-}{ }^{15} \mathrm{~N}$ HSQC spectra of P71T suggested the protein was self-associating [22]. As a function of increasing protein concentration, the region affected was V19-Q32 and as a function of increasing $\mathrm{NaCl}$ concentration, the region first affected was Y26 - Q32. Both these regions overlap with K24 S28, a structural flexible region identified in solid-state NMR studies of the 59-residue splice- 
variant amelogenin LRAP $[50,51]$. Collectively, these studies suggest this region near the Nterminal of amelogenins may be functionally important.

Hydrophobic interactions are an important force driving the proper folding of proteins into their native structure (intramolecularly) and into their associated/aggregated states (intermolecularly) [52]. Consequently, a simple explanation to explain the increased tendency for P71T to self-associate at lower protein and $\mathrm{NaCl}$ concentrations than wild type M180 may be the increase in hydrophobicity due to the replacement of P71 with a more hydrophobic amino acid residue, T. Such an explanation was proposed to explain similar observations with hT21I and hP41T [38], where a $\mathrm{P}$ was also replaced with a $\mathrm{T}(\mathrm{hP} 41 \mathrm{~T})$ and a $\mathrm{T}$ was replaced with an I (hT21I). Using the hydrophobicity index of Kyte and Doolittle [53], the T Q represents a greater increase in hydrophobicity than the P Q The approximately five-fold difference in hydrophobicity increase in hT21I over hP41T and P71T may be primarily responsible for the stronger tendencies of hT21I to self-associate than hP41T and P71T and the same hydrophobicity increase for P71T and h41 may explain their similar self-association properties. Whatever the physical reason, the self-association of the mutants P71T, hT21I, and hP41T at lower protein concentrations and lower ionic strengths than the tagged wild type hM180 may account for the defective enamel associated with amelogenesis imperfecta.

There are a number of ways an increased tendency to self-associate could impair amelogenesis. Premature self-association within ameloblast cells may hinder amelogenin secretion, a mechanism recently reported for the Y34 $\mathrm{CH}$ amelogenin mutation associated with amelogenesis imperfecta [54]. More tightly associated or large nanospheres may interfere with protein-mineral interactions and proteolytic digestion $[26,30]$. Indeed, larger nanospheres that 
are not digested as quickly by MMP20 [28] have been reported for the P70 exT human amelogenin mutation [29]. Disassembly of amelogenin nanospheres may be necessary for proper enamel formation $[55,56]$ and a more tightly associated nanosphere may hinder this disassociation.

In summary, by taking advantage of amelogenin's high solubility in $2 \%$ glacial acetic acid under conditions of low ionic strength it is possible to prepare milligram quantities of untagged, isotopically labeled, recombinant amelogenin. The highest yields are obtained by solubilizing the cell pellet in $6 \mathrm{M}$ guanidine hydrochloride instead of $2 \%$ acetic acid. While relatively pure protein is obtained after extensive dialysis in $2 \%$ acetic acid, because nanosphere formation is sensitive to the interplay of protein concentration and the properties of the solution (ionic strength, $\mathrm{pH}$, solutes, and temperature) [18-22], a final purification step using reverse phase chromatography is recommended. Maximizing the yield of recombinant amelogenin is especially important for preparing isotopically labeled protein for solid-state NMR experiments that can require upwards of 50 milligrams of sample [57]. This improvement in yield afforded by these improved protocols will not only facilitate the purification of peptides and proteins that use amelogenin as a fusion partner [36], but also enable the preparation of large quantities of untagged and isotopically labeled amelogenin for structural and biochemical studies of biomineralization that may lead to the elucidation of the molecular mechanism of enamel formation.

\section{Acknowledgements}


This research was supported by NIH-NIDCH Grant number DE-015347 and performed at the Pacific Northwest National Laboratory (PNNL), a facility operated by Battelle for the U.S. Department of Energy, including access to the W.R. Wiley Environmental Molecular Sciences Laboratory (EMSL), a national scientific user facility sponsored by the U.S. DOE Biological and Environmental Research program.

\section{References}

[1] A.R. Ten Cate, Oral histology: developement, structure, and function, Mosby, St. Louis, 1994.

[2] S.N. White, W. Luo, M.L. Paine, H. Fong, M. Sarikaya, M.L. Snead, Biological organization of hydroxyapatite crystallites into a fibrous continuum toughens and controls anisotrophy in human enamel. J Dent Res 80 (2001) 321-326.

[3] R.C. Shore, J. Robinson, J. Kirkham, S.J. Brookes, Structure of mature enamel, in: C. Robinson, J. Kirkham, R.C. Shore (Eds.) Dental Enamel from Formation to Destruction, CRC Press, Boca Raton, 1995, p. 151.

[4] G. Daculsi, J. Menanteau, L.M. Kerebel, D. Mitre, Length and shape of enamel crystals. Calcif Tissue Int 36 (1984) 550-555.

[5] G. Hunter, Interfacial aspects of biomineralization. Curr Opin Mat Sci 1 (1996) 430-435.

[6] H.C. Margolis, E. Beniash, C.E. Fowler, Role of macromoleculare assembly of enamel matrix proteins in enamel formation. Crit Rev Oral Biol Med 85 (2006) 775-793.

[7] J.P. Simmer, A.G. Fincham, Molecular mechanims of dental enamel formation. Crit Rev Oral Biol Med 6 (1995) 84-108. 
[8] J.D. Termine, A.B. Belcourt, P.J. Christner, K.M. Conn, M.U. Nylen, Properties of dissociatively extracted fetal tooth matrix proteins. J Biol Chem 255 (1990) 9760-9768.

[9] A.G. Fincham, J. Moradian-Oldak, J.P. Simmer, P. Sarte, E.C. Lau, T. Diekwisch, H.C. Slavkin, Self-assembly of a recombinant amelogenin protein generates supramolecular structures. J Struct Biol 112 (1994) 103-109.

[10] A.G. Fincham, J. Moradian-Oldak, T.G.H. Diekwisch, D.M. Lyaruu, J.T. Wright, P.B. Jr., H.C. Slavkin, Evidence for amelogenein "nanospheres" as functional components of secretory-stage enamel matrix. J Struct Biol 115 (1995) 50-59.

[11] T. Uchida, T. Tanabe, M. Fukae, M. Shimizu, M. Yamada, K. Miake, S. Kobayashi, Immunochemical and immunohistochemical studies, using antisera against porcine $25 \mathrm{kDa}$ amelogenin, $89 \mathrm{kDa}$ enamelin and the $12-17 \mathrm{kDa}$ nonamelogenins, on immature enamel of the pig and rat. Histochemistry 96 (1991) 129-138.

[12] E. Beniash, J.P. Simmer, H.C. Margolis, The effect of recombinant mouse amelogenin on the formation and organization of hydroxyapatite crystals in vitro. J Struct Biol 149 (2005) 182190.

[13] B.J. Tarasevich, C.J. Howard, J.L. Larson, M.L. Snead, J.P. Simmer, M.L. Paine, W.J. Shaw, The nucleation and growth of calcium phosphate by amelogenin. J Cryst Growth 304 (2007) 407-415.

[14] S. Toyosawa, F. O'hUigin, F. Figueroa, H. Tichy, J. Klein, Identification and characterization of amelogenin genes in monotremes, reptiles, and amphibians. Proc Natl Acad Sci USA 95 (1998) 13056-13061. 
[15] J. Moradian-Oldak, J. Tan, A.G. Fincham, Interaction of emelogenin with hydroxyapatite cyrstals: an adherence effect through emelogenin self-association. Biopolymers 46 (1998) 225238.

[16] M.L. Paine, S.N. White, W. Luo, H. Fong, M. Sarikaya, M.L. Snead, Regulated gene expression dictates enamel structure and tooth function. Matrix Biol 20 (2001) 273-292.

[17] H.B. Wen, A.G. Fincham, J. Moradian-Oldak, Progressive accretion of amelgenin molecules during nanosphere assembly revealed by atomic force microscopy. Matrix Biol 20 (2001) 387-395.

[18] C. Du, G. Falini, S. Fermani, C. Abbott, J. Moradian-Oldak, Supramolecular assembly of amelogenin nanospheres into birefringent microribbons. Science 307 (2005) 1450-1454.

[19] J. Moradian-Oldak, J.P. Simmer, E.C. Lau, P.E. Sarte, H.C. Slavkin, A.G. Fincham, Detection of monodisperse aggregates of a recombinant amelogenin by dynamic light scattering. Biopolymers 34 (1994) 1339-1347.

[20] J. Moradian-Oldak, W. Leung, A.G. Fincham, Temperature and $\mathrm{pH}$-dependence of amelogin self-assembly: A particle size distribution study. J Struct Biol 122 (1998) 320-327.

[21] F.B. Wiedemann-Bidlack, E. Beniash, Y. Yamakoshi, J.P. Simmer, H.C. Margolis, PH triggered self-assembly of native and recombinant amelogenins under physiological $\mathrm{pH}$ and termperature in vitro. J Struct Biol 160 (2007) 57-69.

[22] G.W. Buchko, B.J. Tarasevich, J. Bekhazi, M.L. Snead, W.J. Shaw, A solution NMR investigation into the early events of amelogenin nanosphere self-assembly initiated with sodium chloride or calcium chloride. Biochemistry 47 (2008) 6571-6582. 
[23] J.T. Wright, M. Torain, K. Long, K. Seow, P. Crawford, M.J. Aldred, P.S. Hart, T.C. Hart, Amelogenesis imperfecta: genotype-phenotype studies in 71 families. Cells Tissues Organs 194 (2011) 279-283.

[24] C.J. Witkop, Jr., W. Kuhlmann, J. Sauk, Autosomal recessive pigmented hypomaturaton amelogenesis imperfecta: report of a kindred. Oral Surg Oral Med Oral Pathol 36 (1973) 367382.

[25] D. Ravassipour, P.S. Hart, T.C. Hart, A.V. Ritter, M. Yamauchi, C. Gibson, J.T. Wright, Unique enamel phenotype associated with amelogenin gene (AMELX) codon 41 point mutation. J Dent Res 79 (2000) 1476-1481.

[26] R. Lakshminarayanan, K.M. Bromley, Y.P. Lei, M.L. Snead, J. Moradian-Oldak, Perturbed amelogenin secondary structure leads to uncontrolled aggregation in amelogenesis imperfecta mutant proteins. J Biol Chem 285 (2010) 40593-40603.

[27] P.M. Collier, J.J. Sauk, J. Rosenbloom, Z.A. Yaun, C.W. Gibson, An amelogenin gene degect associated with human X-linked amelogenesis imperfecta. Arch Oral Biol 42 (1997) 235242.

[28] W. Li, C.W. Gibson, W.R. Abrams, D.W. Andrews, P.K. DenBensten, Reduced hydroylsis of amelogenin may result in X-linked amelogenesis imperfecta. Matrix Biol 19 (2001) 755-760.

[29] L. Zhu, V. Uskokovic, T. Le, P. DenBensten, Y. Huang, S. Habelitz, W. Li, Altered selfassembly and apapite binding of amelogenin induced by N-terminal proline mutation. Arch Oral Biol 56 (2011) 331-336. 
[30] K.M. Bromley, R. Lakshminarayanan, Y.P. Lei, M.L. Snead, J. Moradian-Oldak, Folding, assembly, and aggregation of recombinant murine amelogenins with T21I and P41T point mutations. Cells Tissues Organs 194 (2011) 284-290.

[31] G.W. Buchko, G. Lin, B.J. Tarasevich, W.J. Shaw, A solution NMR investigation into the impaired self-assembly properties of two murine amelogenins containing the point mutations T21I or P41 T. Arch Biochem Biophys 537 (2013) 217-224.

[32] A. Veis, K. Tompkinds, K. Alvares, K. Wei, L. Wang, S. Wang, A.G. Brown, S.-M. Jengh, K.E. Healy, Specific amelogenin gene splice products have signaling effects on cells in culture and in implants in vivo. J Biol Chem 275 (2000) 41263-41272.

[33] M. Zeichner-David, Is there more to enamal matrix proteins than biomineralization? Matrix Biol 20 (2001) 307-316.

[34] S.P. Lyngstadaas, J.C. Wohlfahrt, S.J. Brookes, M.L. Paine, M.L. Snead, J.E. Reseland, Enamel matrix proteins; old molecules for new applications. Orthod Craniofac Res 12 (2009) 243-253.

[35] H.B. Wen, J. Moradian-Oldak, Modification of calcium-phosphate coatings on titanium by recombinant amelogenin. J Biomed Mater Res A 64 (2003) 483-490.

[36] J.S. Bonde, L. Bulow, One-step purification of recombinant human amelogenin and use of amelogenin as a fusion protein. PLos ONE 7 (2012) e33269.

[37] G.W. Buchko, J. Bekhazi, J.R. Cort, N.B. Valentine, M.L. Snead, W.J. Shaw, ${ }^{1}$ H, ${ }^{13}$ C and

${ }^{15} \mathrm{~N}$ Resonance assignments of murine amelogenin, an enamel biomineralization protein. Biomol NMR Assign 2 (2008) 89-91. 
[38] K.M. Bromley, A.S. Kiss, S.B. Lokappa, R. Lakshminarayanan, D. Fan, M. Ndao, J.S. Evans, J. Moradian-Oldak, Dissecting amelogenin protein nanospheres - Charaterization of metastable oligomers. J Biol Chem 286 (2011) 34643-34653.

[39] M.L. Snead, E.C. Lau, M. Zeichner-David, A.G. Fincham, S.L. Woo, H.C. Slavkin, DNA sequence for cloned cDNA for murine amelogenin reveals the amino acid sequence for enamelspecific proteins. Biochem Biophys Res Commum 129 (1986) 812-818.

[40] W.F. Studier, Production of auto-induction in high-density shaking cultures. Protein Expr Purif 41 (2005) 207-234.

[41] T.D. Goddard, D.G. Kneller, Sparky 3, University of California, San Francisco, 1999.

[42] D.S. Wishart, C.G. Bigam, J. Yao, F. Abildgaard, H.J. Dyson, E. Oldfield, J.L. Markley, B.D. Sykes, ${ }^{1} \mathrm{H},{ }^{13} \mathrm{C}$ and ${ }^{15} \mathrm{~N}$ Chemical shift referencing in biomolecular NMR. J Biomol NMR 6 (1995) 135-140.

[43] J.P. Simmer, E.C. Lau, C.C. Hu, P. Bringas, V. Santos, T. Aoba, M. Lacey, D. Nelson, M. Zeichner-David, M.L. Snead, H.C. Slavkin, A.G. Fincham, Isolation and characterization of a mouse amelogenin expressed in Escherichia coli. Calcif Tissue Int 54 (1994) 312-319.

[44] J. Svensson, C. Andersson, J.E. Reseland, S.P. Lyngstadaas, L. Bulow, Histidine tag fusion increases expression levels of active recombinant amelogenin in Escherichia coli. Protein Expr Purif 48 (2006) 134-141.

[45] K. Delak, C. Harcup, R. Lakshminarayanan, Z. Sun, Y. Fan, J. Moradian-Oldak, J.S. Evans, The tooth enamel protein, procine amelogenin, is an intrinsically disordered protein with an extended molecular configuration in the monomeric form. Biochemistry 48 (2009) 22722281. 
[46] G.W. Buchko, B.J. Tarasevich, J. Roberts, M.L. Snead, W.J. Shaw, A solution NMR investigation into the murine amelogenin slice-variant LRAP (Leucine-Rich Amelogenin Protein). Biochim Biophys Acta 1804 (2010) 1768-1774.

[47] M. Ndao, K. Dutta, K.M. Bromley, R. Lakshminarayanan, Z. Sun, G. Rewari, J. Moradian-Oldak, J.S. Evans, Probing the self-association, intermolecular contacts, and folding propensity of amelogenin. Protein Sci 20 (2011) 724-734.

[48] X. Zhang, B.E. Ramirez, X. Liao, T.G.H. Diekwisch, Amelogenin supramolecular assembly in nanospheres defined by a complex helix-coil-PPII helix 3D-structure. PLos ONE 6 (2011) e24952.

[49] M.L. Paine, M.L. Snead, Protein interactions during assembly of the enamel organic extracellular matrix. J Bone Min Res 12 (1997) 221-227.

[50] J.-X. Lu, Y.S. Xu, W.J. Shaw, Phosphorylation and ionic strength alter the LRAP-HAP interface in the N-terminus. Biochemistry 52 (2013) 2196-2205.

[51] J.-X. Lu, S.D. Burton, Y.S. Xu, G.W. Buchko, W.J. Shaw, The flexible structure of the K24S28 region of Leucine-Rich Amelogenin Protein (LRAP) bound to apatites as a function of surface type, calcium, mutation, and ionic strength. Frontiers Phys 5 (2014) 254e.

[52] S. Miller, J. Janin, A.M. Lesk, C. Chothia, Interior and surface of monomeric proteins. J Mol Biol 196 (1987) 641-656.

[53] J. Kyte, R.F. Doolittle, A simple method for displaying the hydrophathic character of a protein. J Mol Biol 157 (1982) 105-132.

[54] M.J. Barron, S.J. Brookes, J. Kirkham, R.C. Shore, C. Hunt, A. Mironov, N.J. Kingswell, J. Maycock, C.A. Shuttleworth, M.J. Dixon, A mutation in the mouse Amelx tri-tyrosyl domain 
results in impaired secretion of amelogenin and phenocopies human X-linked amelogenesis imperfecta. Hum Mol Genet 19 (2010) 1230-1247.

[55] B.J. Tarasevich, S. Lea, W.J. Shaw, The leucine rich amelogenin protein (LRAP) adsorbs as monomers or dimers onto surfaces. J Struct Biol 169 (2010) 266-276.

[56] B.J. Tarasevich, U. Perez-Salas, D.L. Masica, J. Philo, P. Kienzle, S. Krueger, C.F. Majkrzak, J.L. Gray, W.J. Shaw, Neutron reflectrometry studies on the adsorbed structure of the amelogenin, LRAP. J Phys Chem B 117 (2013) 3098-3109.

[57] J.-X. Lu, Y.S. Xu, G.W. Buchko, W.J. Shaw, Mineral association changes the secondary structure and dynamics of murine amelogenin. J Dent Res 92 (2013) 1000-1004. 


\section{Figure legends}

Fig. 1. Primary amino acid sequence of murine amelogenin highlighting the three major regions of the protein: N-terminal tyrosine-rich region, TRAP (cyan); hydrophobic central region rich in P, L, H, and Q residues, HQP-rich region (grey); and a hydrophilic C-terminal region (magenta). The acidic residues are colored red, basic residues colored blue, and the lone serine that is phosphorylated in vivo is colored yellow. The location of amino acid substitutions in three point mutations associated with Amelogenesis imperfecta, T21 टll (hT21I), P41 टाT (hP41T), and P71 टी (P71T), are indicated by a blue box.

Fig. 2. A $8-16 \%$ Tris-HCl SDS-PAGE gel illustrating the purity of selected fractions during stages in the purification protocol for P71T. Lane A - After heating and pre-dialysis; Lane 0 Supernatant of A after centrifugation (0x dialysis); Lane 1 - Supernatant following first 1:250 (v:v) dialysis in 1\% acetic acid (1x dialysis); Lane 2 - Supernatant follow second first 1:250 (v:v) dialysis in 2\% acetic acid (2x dialysis); Lane $\mathrm{G}-6 \mathrm{M}$ guanidine hydrochloride recovery of precipitants from Lane 2 fraction dialyzed $2 \mathrm{x}$ in 2\% acetic acid (1:250, v:v); Lane 3 - Reverse phase HPLC purification of Lane 2 supernatant; Lane 4 - Reverse phase HPLC purification of Lane G supernatant; $\mathrm{M}$ - molecular weight markers.

Fig. 3. Reverse-phase HPLC chromatogram profiles for P71T (A) and M180 (B) illustrating the improvement in yields due to dialysis in $2 \%$ acetic acid and cell lysis with $6 \mathrm{M}$ guanidine hydrochloride, respectively. In both chromatograms the major band eluting at $\sim 36$ min contains 
the amelogenin protein and corresponds to $\sim 68 \%$ Buffer $\mathrm{B}$ (70\% aq. $\mathrm{CH}_{3} \mathrm{CN}$ in $0.1 \%$ ). (A) Soluble fraction of the cell lysis material from P71T, prepared by heating in $2 \%$ acetic acid, following centrifugation without (red) and with (black) extensive dialysis in $1-2 \%$ acetic acid. (B) Soluble fraction of the cell lysis material from M180, prepared by heating in equal volumes of $2 \%$ acetic acid (black) or $6 \mathrm{M}$ guanidine hydrochloride (purple).

Fig. 4. (A) Overlay of the ${ }^{1} \mathrm{H}-{ }^{15} \mathrm{~N}$ HSQC spectrum of M180 (black) and hM180 (red) collected under similar experimental conditions $(0.3 \mathrm{mM}$ protein concentration, $2 \%$ acetic acid, $\mathrm{pH} \mathrm{2.8,20}$ ${ }^{\circ} \mathrm{C}$ ) at a ${ }^{1} \mathrm{H}$ resonance frequency of $750 \mathrm{MHz}$. The resonances for the 12-residue, N-terminal poly-histidine tag in hM180 are labeled in red and with an asterisk. Aside form the N-terminal tag, the most significant difference between the spectra of the two proteins is the resonance for L3 circled in blue.

Fig. 5. Overlay of the ${ }^{1} \mathrm{H}-{ }^{15} \mathrm{~N}$ HSQC spectra of M180 (black) and P71T (yellow) collected under similar experimental conditions $\left(0.3 \mathrm{mM}\right.$ protein concentration, $2 \%$ acetic acid, $\left.\mathrm{pH} 2.8,20^{\circ} \mathrm{C}\right)$ at a ${ }^{1} \mathrm{H}$ resonance frequency of $750 \mathrm{MHz}$. The amide resonances with the most significant chemical shift differences are circled in blue and labeled. The T71 resonance in P71T, indicated with a blue arrow, overlaps with the $\mathrm{H} 91$ amide resonance.

Fig. 6. Summary of the amide resonances that partially disappear (grey-filled circles) or completely disappear (open circles) in the ${ }^{1} \mathrm{H}-{ }^{15} \mathrm{~N}$ HSQC spectra of ${ }^{15} \mathrm{~N}$-labelled hP41T, hT21I, and P71T when the concentration of the protein is increased from 0.1 to $1.8 \mathrm{mM}$. Amide cross 
peaks whose intensity change little over the concentration range are indicated by solid circles and cross peaks that could not be tracked unambiguously are indicated by green-filled circles. The full murine amelogenin sequence is shown with the proline residues highlighted in cyan and the site of the individual point mutations in each protein highlighted in red. Underneath the primary sequence is a schematic illustration of the three major regions of the protein: TRAP region (cyan); HQP-rich region (grey); and hydrophilic C-terminal region (magenta). The data for hP41T and hT21I were published previously [31].

Fig. 7. Summary of the amide resonances that partially disappear (grey-filled circles) or completely disappear (open circles) in the ${ }^{1} \mathrm{H}-{ }^{15} \mathrm{~N}$ HSQC spectra of ${ }^{15} \mathrm{~N}$-labelled P71T as a function of increasing $\mathrm{NaCl}$ concentration. Amide cross peaks whose intensity change little over the concentration range are indicated by solid circles and cross peaks that could not be tracked unambiguously are indicated by green-filled circles. The $\mathrm{NaCl}$ :P71T molar ratio are shown on the left. The full murine amelogenin sequence is shown with the proline residues colored cyan and the site of the P71 28T point mutation highlighted in red. Underneath the primary sequence is a schematic illustration of the three major regions of the protein: TRAP region (cyan); HQP-rich region (grey); and hydrophilic C-terminal region (magenta). 
MPLPPHPGSP GYINL §YEVL TPLKWYQSMI RQPYPSYGYE PMGGWLHHQI IPVLSQQHPP SHTLQPHHHL PVVPAQQPVA PQQPMMPVPG HHSMTPTQHH QPNIPPSAQQ PFQQPFQPQA IPPQSHQPMQ PQSPLHPMQP LAPQPPLPPL FSMQPLSPIL PELPLEAWPA TDKTKREEVD 


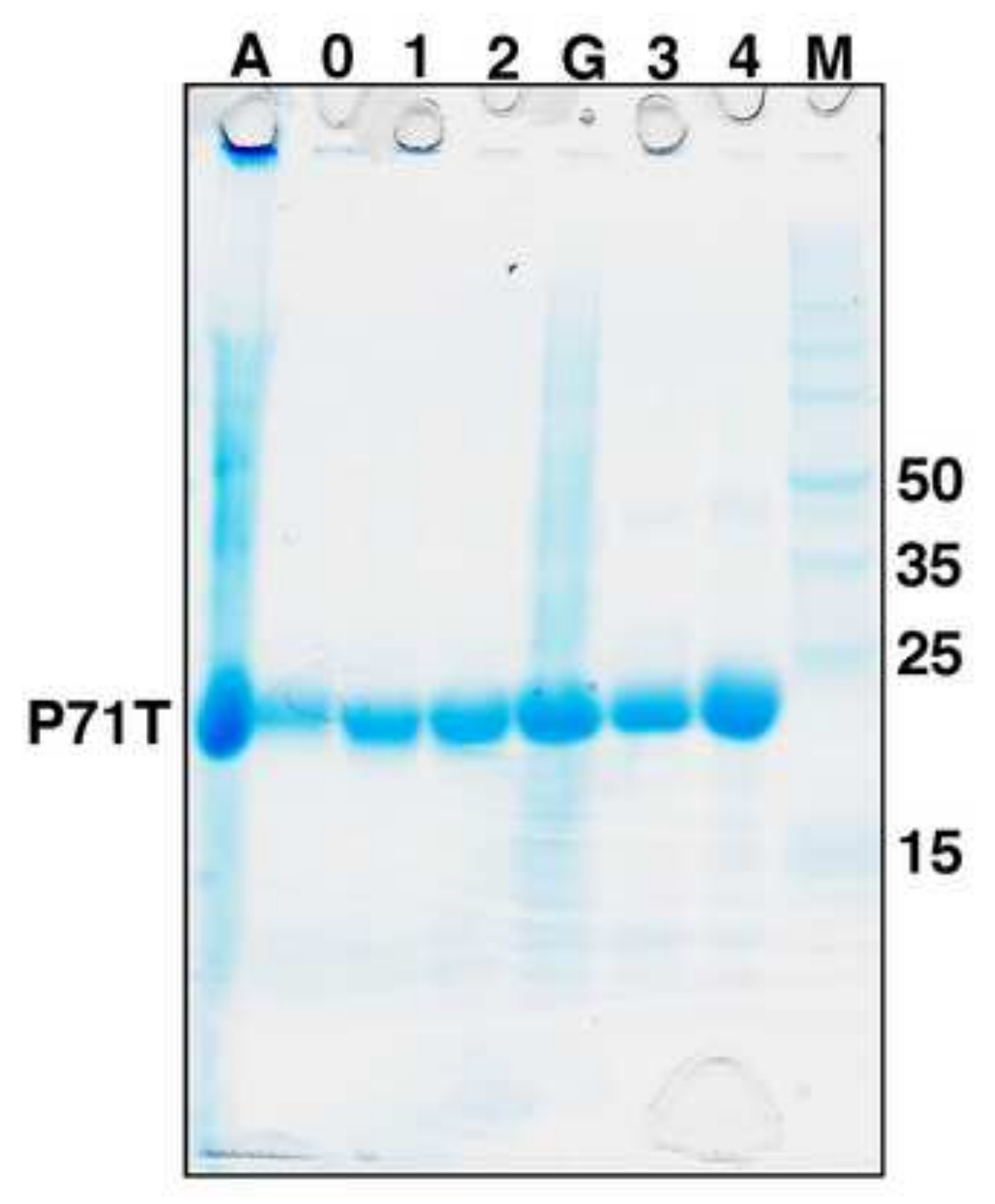



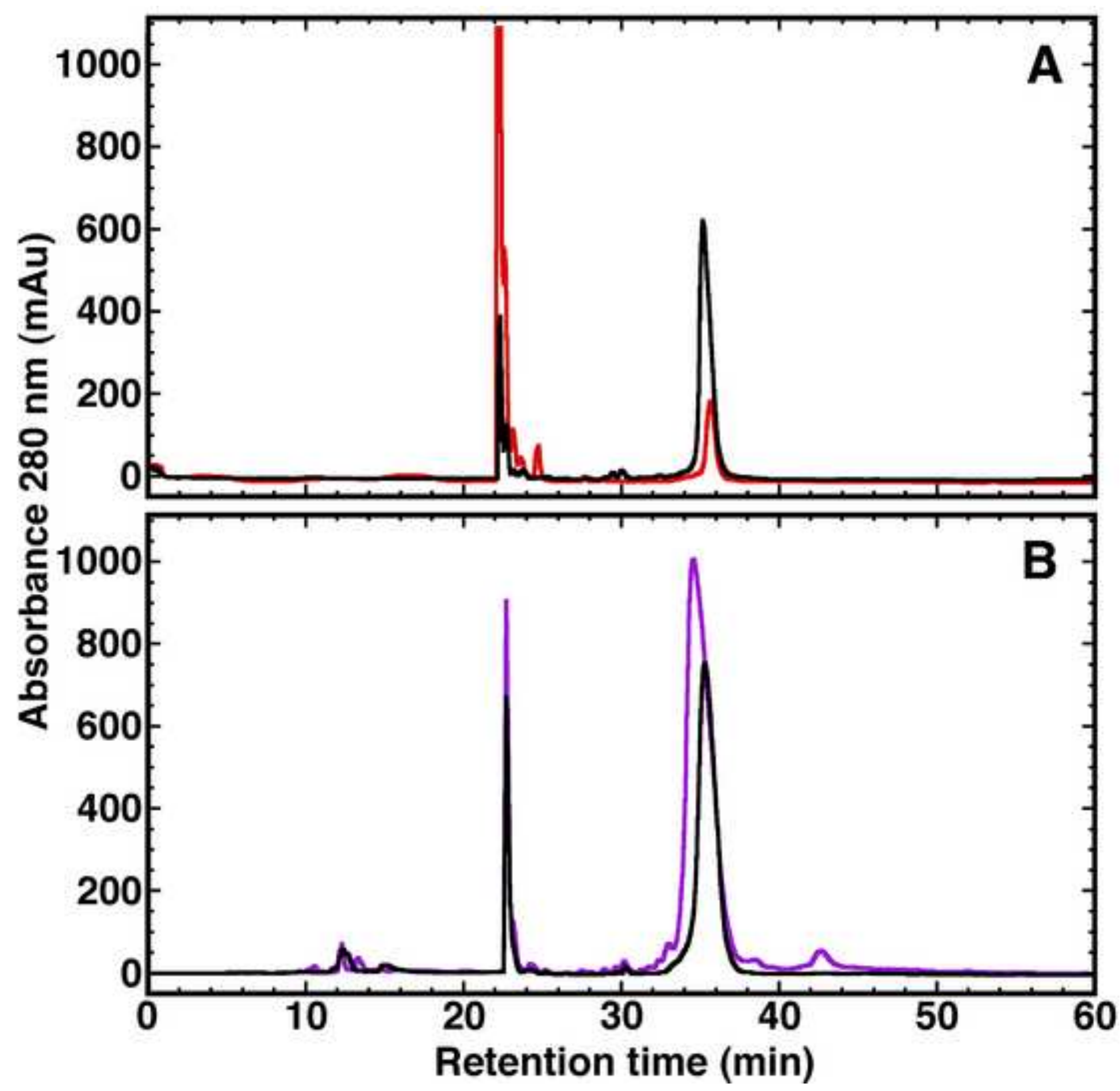


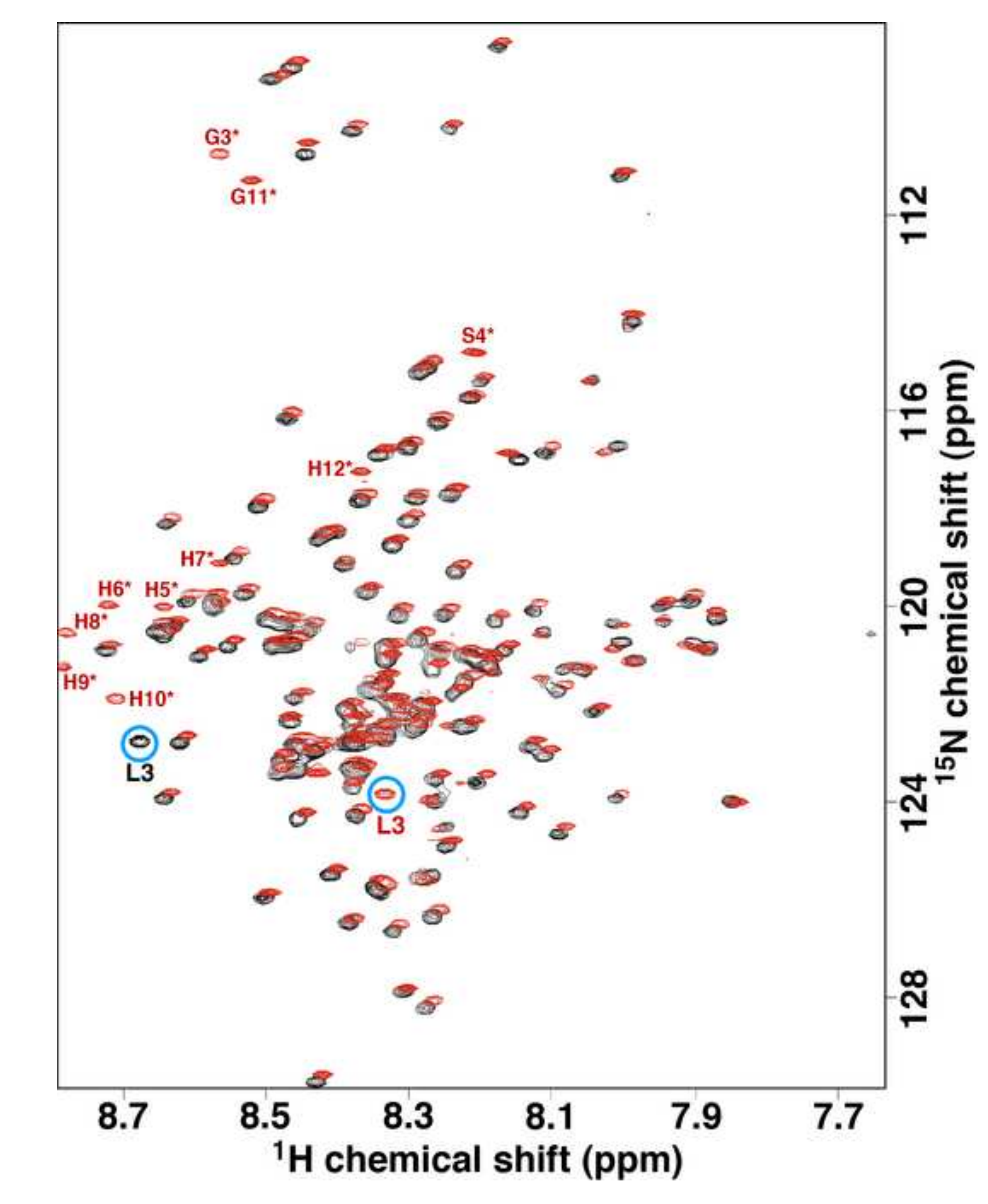

Figure 4
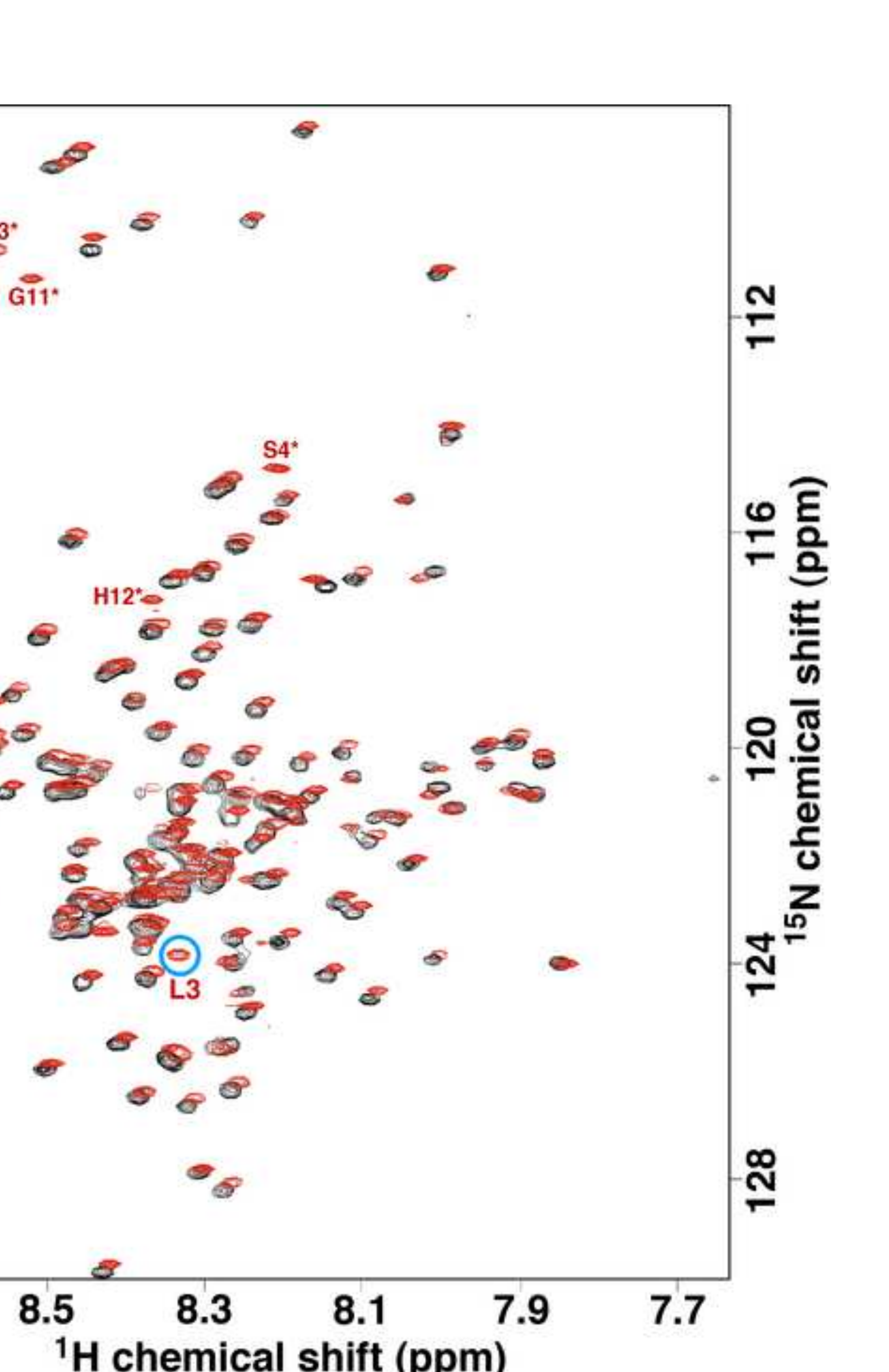

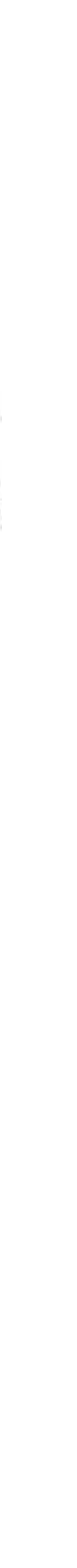




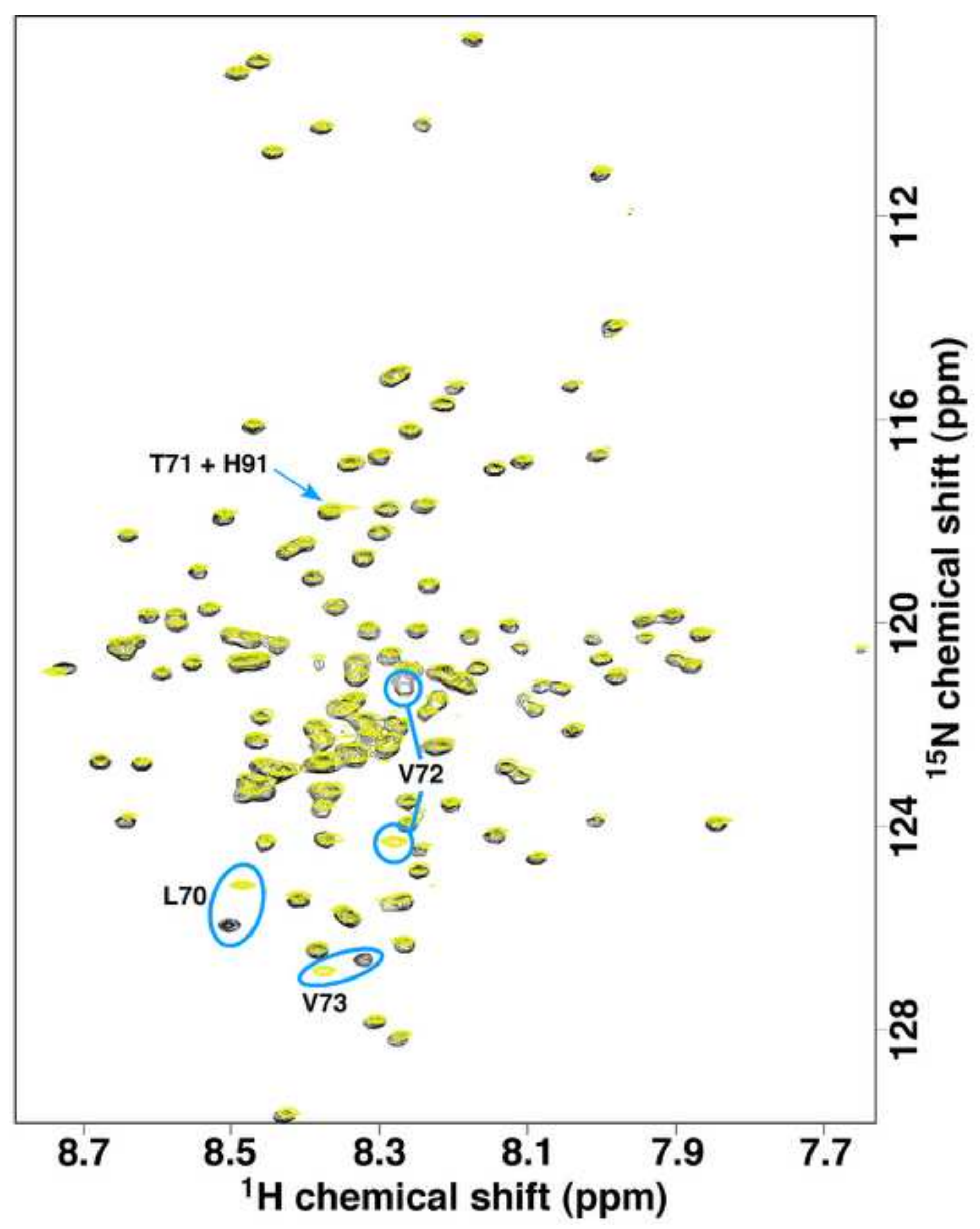

Figure 5 


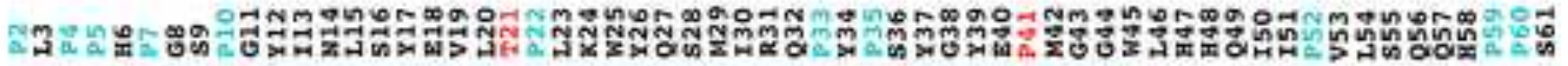

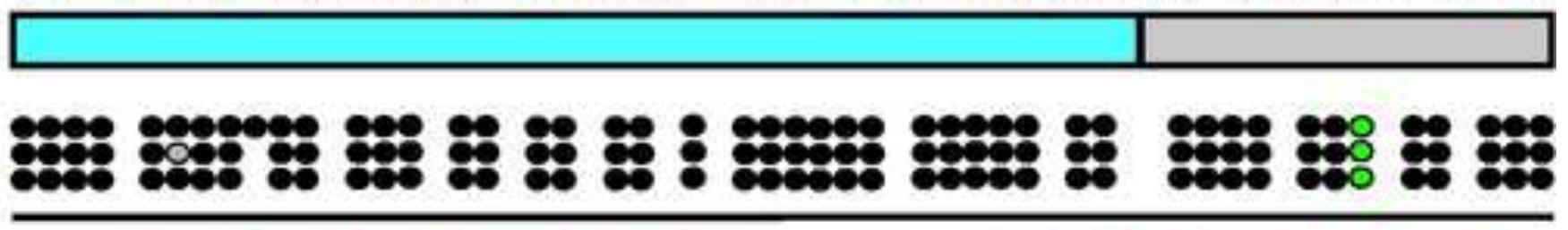

Nกำ

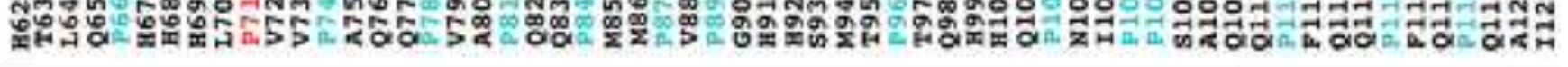

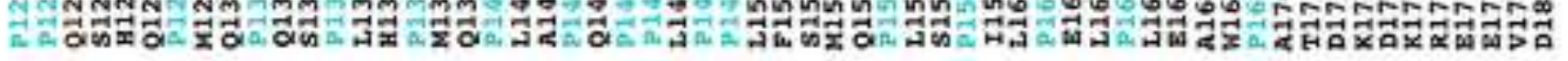

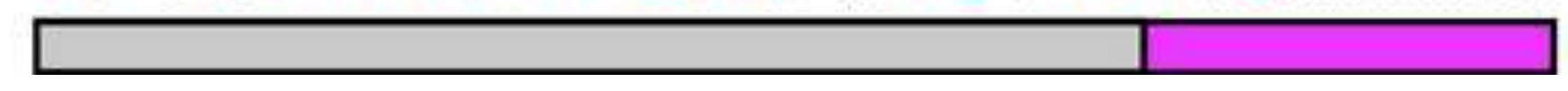


$1800: 1-$ 1600:1 $1400: 1$ $1200: 1$ 1000:1 -

$800: 1$ -

600:1 -

$400: 1$ -

\%00000 000000000 \%ం잉 00000000 0000000 \%00000000
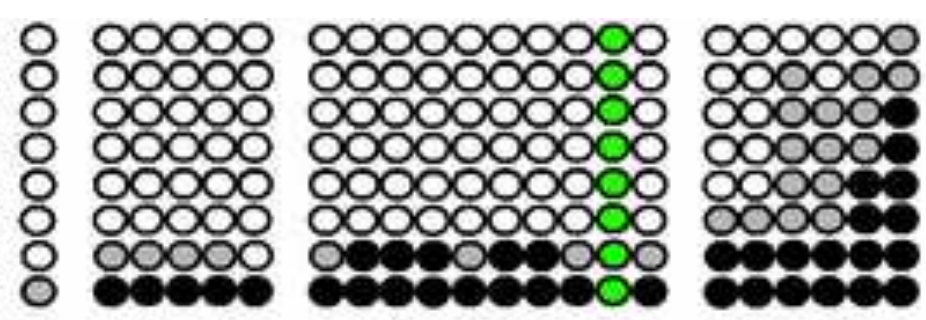

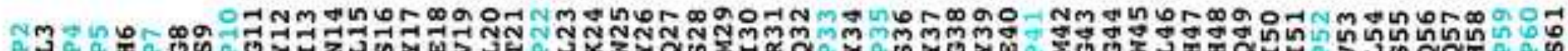

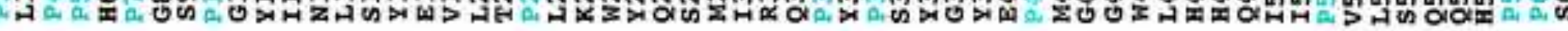

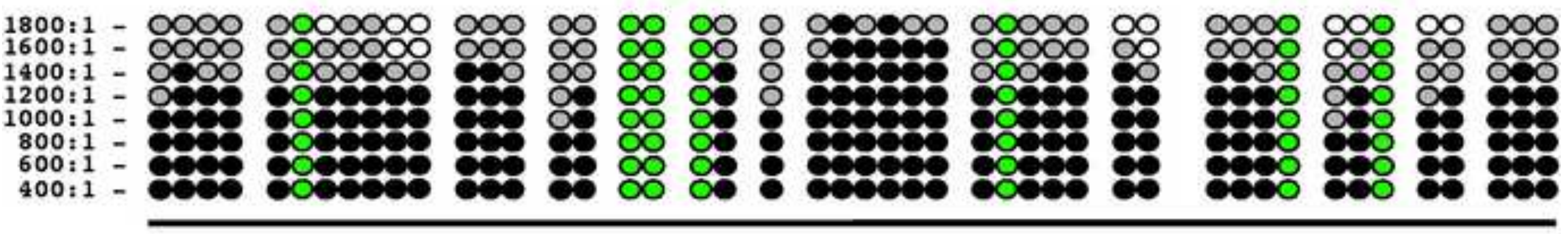

Nmㄴ

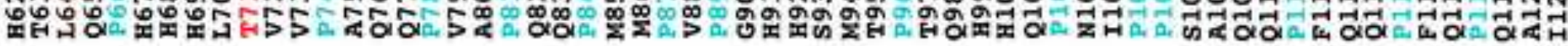

$1800 \div 1-$ $1600: 1-$ $1400: 1-$ $1200: 1-$ 1000:1 -

$800: 1-$ $600: 1-$ $400: 1$ -
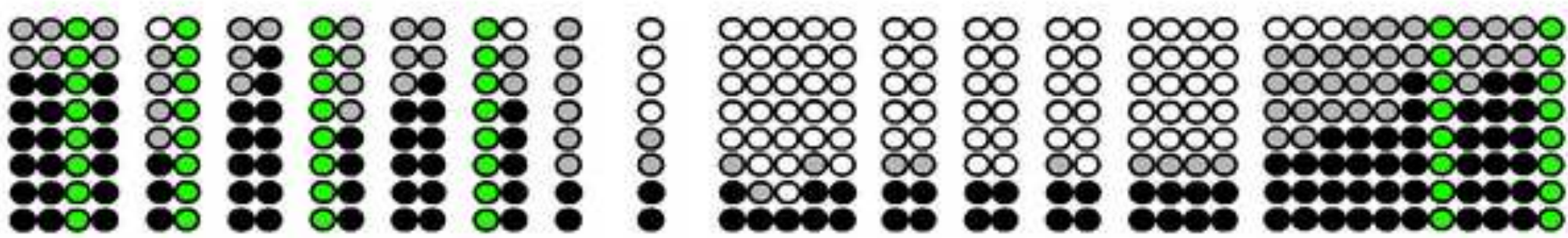

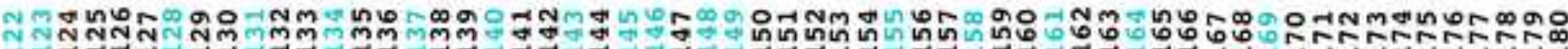

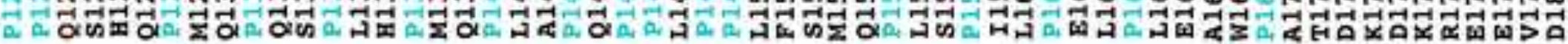
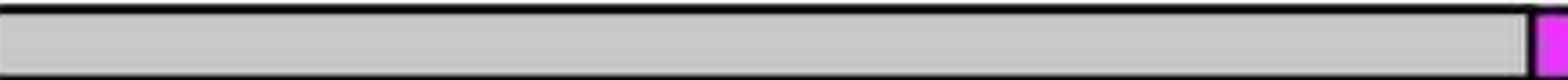